\title{
Patterns of Internet and smartphone use by parents of children attending a pediatric ptolaryngology service
}

\section{A R T I C L E I N F O}

\section{Article history:}

Received 28 September 2012

Received in revised form 16 January 2013

Accepted 18 January 2013

Available online xxx

\section{Keywords:}

Internet

App cript

Internet Script

Smartphone

eHealth

mHealth

\begin{abstract}
A B S T R A C T
Objectives: To assess Internet use and the influence of smartphones on health-information seeking by parents and carers of children with ENT conditions.

Methods: A paper-based questionnaire was circulated to parents attending otolaryngology services in both the out-patient and day-case settings at a tertiary referral centre.

Results: $79.5 \%$ of questionnaires were returned. $29.9 \%$ had consulted the Internet for ENT-related information. Factors associated with increased rates of ENT-related online activity included younger age, university education, and access to a smartphone (all $p \leq 0.001$ ). $65.7 \%$ and $57.7 \%$ had found the information which they had found online to be understandable and helpful, respectively; however, just $25.5 \%$ felt that it had influenced the medical decisions they had made for their child. $50.3 \%$ had previously or intended to discuss information found online with their surgeon. $9.2 \%$ had searched online for information regarding their child's surgeon; $19.6 \%$ of these said that this had been a factor in choosing that particular surgeon. On ranking 8 information sources in terms of importance (scale 0-5), the ENT Surgeon ranked as most important (mean $=4.63$ ), whilst the Internet ranked lowest $(3.10) .48 .6 \%$ of respondents or their partners had an Internet-enabled smartphone; $45.2 \%$ said they would definitely use an iPhone app regarding their child's condition if one was available. $36.1 \%$ reported they would definitely use the Internet in the future.

Conclusions: Whilst online sources must increasingly be considered in the dialogue with parents, it is clear that parents still rate the clinical team as most important for information gathering. Clinicianprovided websites and smartphone applications may be the key to ensuring the provision of quality information into the future.
\end{abstract}

(c) 2013 Elsevier Ireland Ltd. All rights reserved.

\section{Introduction}

Eurostat have recently reported that more than half of individuals (56\%) in the EU use the Internet everyday or almost every day, whilst $68 \%$ now go online at least once a week [1]. A key driver in the growth of the Internet has been the introduction of Internet-enabled 'smartphones', and these devices are now emerging as everyday platforms for accessing information and managing daily routines; there are now an estimated 1.08 billion smartphones globally, with $84 \%$ of users using their devices to browse online, and 69\% downloading applications [2].

eHealth, and use of the Internet as a source of health information, has been postulated to present a range of benefits

\footnotetext{
* Corresponding author. Tel.: +353 85 1996008; fax: +3531 8784502 .

E-mail address: ${ }^{\wedge}$ ronanglynn@doctors.net.uk (R.W. Glynn).

1 Oral Presentation at: European Society for Pediatric Otorhinolaryngology (ESPO), Amsterdam, The Netherlands. 23rd May 2012.
}

to the end-user, including supplementation of information received from a health practitioner, the provision of anonymity in health information-seeking, a means of information exchange and community support, and empowerment in seeking help for, and understanding, medical conditions [3]. 80\% (113 million individuals) and 54\% of American and European Internet users employ the Internet to access health information, respectively, $[1,4]$ and those who use the Internet to search for information regarding a personal health problem are $60 \%$ more likely to contact a health professional compared with those who have not searched online [5].

A subsection of eHealth, mobile or mHealth, may be defined as "the use of wireless communication devices to support public health and clinical practice" [6], with eight mHealth domains identified - education and awareness systems, point-of-care support and diagnostics, patient monitoring, disease and epidemic outbreak surveillance, emergency medical response systems, health information systems for management of clinical data, educational support for health professionals (mLearning), and

0165-5876/\$ - see front matter ๑ 2013 Elsevier Ireland Ltd. All rights reserved. http://dx.doi.org/10.1016/j.ijporl.2013.01.021 
health financing with applications which facilitate the use of smart cards or vouchers for mobile payments $[7,8]$. One recent study has suggested a doubling in mHealth use by the U.S. population between 2010 and 2012 [9], and the 2012 Healthcare Innovation and Marketplace Technologies Bill in the United States has called for the establishment of an office at the U.S. Food and Drug Administration specializing in mobile health.

Within otolaryngology, a number of papers have examined Internet use by patients in both the out- $[10-12]$ and in-patient settings [13]. Just one, however, has examined its use as an information source for parents of children attending a paediatric otolaryngology service, and this was in the day-case setting only [14]. Only one study has examined patterns post-2007, and none have examined the use of smartphones as a means of obtaining relevant information. This present work thus aimed to determine contemporary trends in traditional and online health-information seeking by parents of children attending both out-patient clinic and day-case otolaryngology services at a tertiary referral centre.

\section{Methods}

A paper-based questionnaire, modelled on those employed by Boston et al. and Tassone et al. [10,14], was circulated to parents attending Otolaryngology services in both the out-patient and daycase settings at the Children's University Hospital, Temple Street, Dublin, between October and November 2011. Ethical approval for the study had been sought and obtained from the Hospital's Ethics Committee. Parents who had completed the questionnaire in the out-patient setting were not asked to submit a second form on the day-case unit. Data was entered into a database and analysed using Excel and SPSS software. Where responses were left blank, they were excluded from data analyses, and percentages were expressed relative to the number of respondents who answered individual questions. The Chi-squared and Mann-Whitney $U$ tests were employed to assess for significant differences; $p$-values less than 0.05 were considered significant.

\section{Results}

79.5\% ( $n=501$ ) of questionnaires were returned, 351 from the out-patients department and 150 from the day-case unit. Demographic data is presented in Table 1.

\subsection{General patterns of Internet use}

$4.4 \%$ (22/500) respondents reported that they had no access to the Internet; $69.4 \%(n=347)$ had access at home. Whilst just $1.4 \%$ $(n=7)$ reported access at work only, $21.6 \%(n=108)$ reported access at home and at work. $1.8 \%(n=9)$ used their public library

Table 1

Demographic data.

\begin{tabular}{|c|c|c|c|}
\hline Relationship to chilc & & Education level & \\
\hline Mother & 378 & National School & 23 \\
\hline Father & 112 & Junior Certificate & 75 \\
\hline Grandparent & 3 & Leaving Certificate & 215 \\
\hline Sibling & 3 & (High School Completion) & \\
\hline Mother and father & 3 & University Graduate & 178 \\
\hline${ }_{\Lambda}$ Foster parent & 2 & Unknown & 10 \\
\hline Age & & $\Lambda_{\Lambda}^{\text {Private health insurance }}$ & \\
\hline$<18$ & 5 & Yes & 182 \\
\hline $18-40$ & 341 & No & 315 \\
\hline $41-65$ & 153 & Unknown & 4 \\
\hline$>65$ & 1 & & \\
\hline Unknown & 1 & & \\
\hline
\end{tabular}

for access, with the remainder $(1.4 \%, n=7)$ using a combination of home or work and the public library to get online.

$72.2 \%(358 / 496)$ and $16.9 \%(n=84)$ employed the Internet on a daily or weekly basis, respectively; $1.8 \%(n=9)$ used it on a monthly basis, and $9.1 \%(n=45)$ only went online very rarely.

\section{2. mHealth}

$48.6 \%$ (243/500) of respondents reported that they or their partner had a phone with Internet access; those with access to a smartphone were significantly more likely to browse online on a daily basis versus those without such access; (195/243 (80.2\%)) versus $(163 / 253)(64.4 \%))(p<0.001)$. Those with access to a smartphone were also significantly more likely to have searched online for pertinent health information, (89/241 (36.9\%)) versus $(60 / 256(23.4 \%))(p=0.001)$.

\subsection{Patterns of online otolaryngology-related behaviour}

$29.9 \%(149 / 497)$ of respondents had searched online for information regarding their child's ENT problem. 36.7\% (54/147) of those attending for a day-case procedure had employed the Internet for information related to the procedure, whilst $27.1 \%$ (95/ 350 ) of those attending the outpatient department had browsed online. $30 \%(105 / 350)$ of those attending this department were doing so for the first time; $20.9 \%(n=22)$ had been online prior to this initial attendance. $34.8 \%$ (120/344) of those aged 40 or less had searched online in relation to their child's condition or symptoms; this compared with $19.1 \%$ (29/152) of those aged between 41 or older $(p<0.001) .44 .3 \%(78 / 176)$ of respondents who had a postgraduate education had searched online; this compared with $22.1 \%(69 / 311)$ of those who had left formal education at an earlier stage $(p<0.001)$. Those with private health insurance were significantly more likely to have searched online for ENT-related information; 39.1\% (70/179) of those insured privately consulted the Internet compared with $24.8 \%$ (78/315) of those who did not hold private insurance $(p=0.001) .35 .9 \%(128 / 356)$ of daily Internet users had searched online for relevant information versus $15.3 \%(21 / 137)$ of those who used the Internet less frequently $(p<0.001)$.

When asked if the information they had found online was understandable, $65.7 \%(94 / 143)$ agreed, 25.2\% $(n=36)$ partially agreed, $7.7 \%(n=11)$ were uncertain, and $1.4 \%(n=2)$ disagreed. When asked if the information was helpful, $57.7 \%(82 / 142)$ of respondents agreed, 30.3\% $(n=43)$ partially agreed, 9.9\% $(n=14)$ were uncertain, and $2.1 \%(n=3)$ disagreed. When the parents or carers were asked if what they had learnt online had influenced the treatment decisions they had made for their child, $25.5 \%(36 / 141)$ agreed that it had, 29.8\% $(n=42)$ partially agreed, $15.6 \%(n=22)$ were uncertain, and $29.1 \%(n=41)$ disagreed. $50.3 \%(71 / 141)$ of respondents had discussed or intended to discuss the information which they had found online with their surgeon.

Of 499 respondents, $9.2 \%(n=46)$ had searched online for information regarding their child's surgeon; $19.6 \%(n=9)$ of these reported that what they had found had influenced their choice of surgeon.

\subsection{Comparison with traditional information sources}

Respondents were asked to rank 8 information sources on Likert-type scales ranging from 0 (did not use) to 5 (very important) in terms of importance; the ENT surgeon was ranked as most important (mean $=4.63$ ), followed by the general practitioner (4.14), paediatrician (4.09) and ENT nurse (4.06), whilst the Internet ranked lowest (3.10)(Fig. 1). The importance placed on the Internet was not affected by age $(p=0.209)$, 


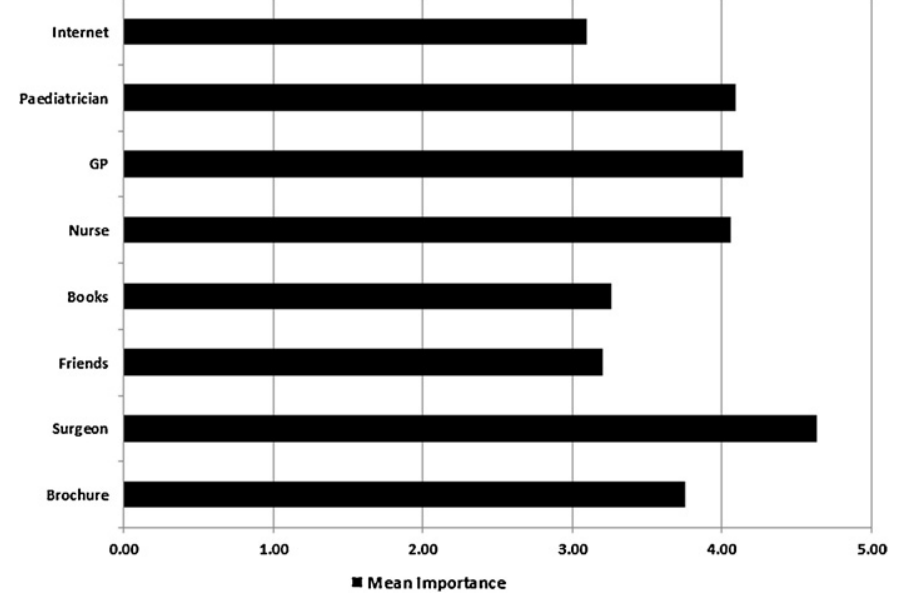

Fig. 1. Mean importance of information sources in finding information.

141

142

143

144

145

146

147 attainment of postgraduate education $(p=0.610)$, or insurance status $(p=0.846)$. Respondents attending the day-case unit were asked specifically if they had received an information leaflet relating to their child's condition or proposed procedure; $63.6 \%$ $(96 / 150)$ reported that they had, and these respondents gave the leaflets a mean score of 3.99 in terms of importance in information gathering.

\subsection{Future plans}

When asked if they would use the Internet in the future to search for information regarding their child's health, $36.1 \%$ (178/ 493) reported that they definitely would, $49.6 \%(n=245)$ said that they may do, and $14.4 \%(n=70)$ said that they would not. When asked if they would use a smartphone application with information regarding their child's ENT problem, were it to be developed, $45.2 \%$ of respondents reported that they would definitely use it, whilst $38.5 \%(n=190)$ said they would consider it, and $16.2 \%$ $(n=80)$ said that they would not use it.

\section{Discussion}

The study has reiterated the increasing ubiquity of the Internet, with just $4.4 \%$ of respondents having no access to it at all, and over $92 \%$ able to go online at home. Our finding that $29.9 \%$ of respondents had searched online for information regarding their child's symptoms or condition correlates well with that of recent work by Shaw et al., in the adult setting, in the UK (32\%) [11]. Significant predictors of health information seeking activity online were younger age ( $\leq 40$ years), higher level of educational attainment, private insurafice status, daily Internet use, and access to an Internet-enabled smartphone. This latter factor appears to be a key driver in Internet use, with over $80 \%$ of those with access to these devices going online on a daily basis. Given the aforementioned ubiquity of smartphone coverage, and the fact that coverage is weighted towards younger age, it is plausible that the vast majority of parents will have access to this technology in the near future; one author has estimated that $80-90 \%$ of the UK population will have a smartphone in 10 years [15].

Whilst Internet use generally, and health seeking use in particular, may be on the rise, doubts have been raised as to the quality or otherwise of the information which patients or their carers encounter online [16,17]. Within otolaryngology, Chestnutt and Pothier et al. have reported on the poor readability of websites relating to common oral pathologies [18] and glue ear [19], respectively, whilst Volsky et al. demonstrated content accuracy on common ENT diagnoses in MedlinePlus and Wikipedia of just $49 \%$ and $46 \%$, respectively [20]. This present work has found that over $90 \%$ of those who had searched online for health information at least partially agreed that the information found was understandable, with a similar number $(88 \%)$ agreeing that the information was at least somewhat helpful. In contrast, however, $29.1 \%$ felt that the information found online would not influence the treatment decisions which they would make for their child, although over half had discussed or intended to discuss information found online with their surgeon. This latter finding highlights the importance of clinician awareness in relation to patient's online activity; such activity will increasingly mandate the adoption of the shared clinical decision making model between patient/carer and doctor. That said, the encroachment of the Internet into medical practice need not be seen as a negative by doctors for, as pointed out by Hartzband and Groopman in a treatise on the significance of the Internet for physicians, it is they who "are in the best position to weigh information and advise patients, drawing on their understanding of available evidence as well as their training and experience....if anything, the wealth of information on the Internet will make such expertise and experience more essential" [21].

Despite the widespread use of the Internet, respondents still ranked it less important relative to traditional sources of health information. As noted elsewhere [14,22], the clinician remains the most important source of information for parents. One limitation of this work is that we did not ask parents if they trusted the information found online; certainly, it appears from the results of other studies that parents mistrust this information [22], and this may well explain the relative lack of importance placed on material found online. There thus appears to exist an opportunity for clinicians to become the gateway to the Internet for parents; it seems plausible that if parents trust their clinicians, they will thus trust those websites to which they are directed by their clinicians. Healthcare professionals have considerable experience in weighing up information and evaluating the evidence base for individual treatments or management strategies; the next step will be to utilise this experience in the evaluation of online information such that we can identify those websites which are (a) accurate and (b) complete, and then pass this information to our patients. More importantly, we can identify those websites which are potentially damaging to the patient or parent, and subsequently advise them to avoid visiting those sites. Clinicians can thus provide an "Internet prescription" for the parent or patient [23], thereby reducing consultation times and improving the process of informed consent and patient-doctor collaboration. This approach is all the more important when one considers that up to $80 \%$ of information given to patients is forgotten [24]; $70 \%$ of patients were unable to remember a single possible complication associated with their procedure on the day of surgery in one study of ENT patients at one UK university teaching hospital [25].

Whilst $29.9 \%$ of respondents had used the Internet to search for information regarding their child's ENT problem, $85.7 \%$ of respondents said that they would possibly or definitely use it in the future as an information source. Similarly, $83.7 \%$ of patients reported that they would at least consider using a disease specific smartphone application containing relevant information. For clinicians who are wary of prescribing Internet content, an "appscript" may be a more palatable alternative in that the information therein can be controlled by the clinician. Unfortunately, whilst a number of patient-specific apps have been developed within ENT, including those which allow the patient to can test their own hearing (uHear [Unitron Hearing Ltd.), selfassess for sleep apnoea (Sleep Assess [ResMed]), self-manage tinnitus (iTinnitus [Inner ear solutions]), and find information on 
different ENT-related conditions (Sinusitis [Dr. Kenny Pang]), ENTDecide ${ }^{\mathrm{TM}}$ [Orca MD], and 'Patient.co.uk'), the majority of these applications have not been independently assessed and validated for content and accuracy. In addition, within the realm of pediatric ENT specifically, very little has yet been developed which might reasonably aid the parent/carer in learning about a particular condition or treatment. On the otherhand, however, there are now a myriad of smartphone applications available which have been developed with doctors in mind, among them a multitude designed specifically for otolaryngologists [26]; as we increasingly adopt this technology in improving our own knowledge and efficiency, the practice of developing and "prescribing" patient-centred applications may well become an accepted component within the overall process of information provision.

\section{Conclusion}

This work has demonstrated the pervasive growth of the Internet and mobile health and their increasing influence on healthcare provision in the setting of pediatric otolaryngology. It is clear that these advances are set to continue, and hence clinicians must be cognisant of this growth and attempt to harness it, to enhance both the doctor-patient relationship and the related processes of information delivery and informed consent.

\section{Conflicts $\Lambda$ of interest}

$\Lambda^{\text {None. }}$

\section{Acknowledgements}

The authors would like to acknowledge Mairead O' Leary and Linda Tighe for their contribution to this article.

\section{References}

[1] H. Seybert, Internet usage in 2011 - households and individuals, Eurostat (2011).

[2] Smartphone users around tĥ́e world - statisticś and facts. http://www.go-gulf.com/blog/smartphone. Accessêd 17/06/2012.

[3] S. Gallagher, D. Tedstone Doherty, R. Moran, Y. Kartalova-O'Doherty, Internet use and seeking health information online in Ireland: demographic characteristics and mental health characteristics of users and non users. in: HRB Research Series 4, Health Research Board, Dublin, 2008.
[4] J. Hay, E.J. Coups, J. Ford, M. DiBonaventura, Exposure to mass media health information, skin cancer beliefs, and sun protection behaviors in a United States probability sample, J. Am. Acad. Dermatol. 61 (2009) 783-792.

[5] M.L. Ybarra, M. Sumân, Help seeking behavior and the Internet: a national survey, Int. J. Med. Inf. 75 (2006) 29-41.

[6] J.G. Kahn, J.S. Yang, J.S. Kahn, 'Mobile' health needs and opportunities in developing countries, Health Aff. (Millwood) 29 (2010), 254-Û236.

[7] A.J. Barton, The regulâtion of mobile health applications, BMC Med. 10 (2012).

[8] Royal Tropical Institute: What is ${ }_{\Lambda}$ Health? http://www. mhealthinfo.org/whatmhealth.

[9] S. Fox, M. Duggan, Mobile health. Pew Internet \& American Life Project, 11/8/2012. http://www.pewinternet.org/Reports/2012/Mobile-Health.aspx, Accessed 6.01. 2013.

[10] P. Tassone, C. Georgalas, N.N. Patel, E. Appleby, B. Kotecha, Do otolaryngology outpatients use the Internet prior to attending their appointment? J. Laryngol. Otol. 118 (2004) 3ै4-38.

[11] B. Shaw, A. Farboud, A. Trinidade, P. Kothari, Internet and e-mail use in ENT: a survey of patient usage and satisfaction, Eur. Arch. Otorhinolaryngol. 269 (2012) 1051-1054.

[12] A. Rokade, P.K.D. Kapoor, S. Rao, V. Rokade, K.T.V. Reddy, B.N. Kumar, Has the Internet overtaken other traditional sources of health information? Questionnaire survey of patients attending ENT outpatient clinics, Clin. Otolaryngol. 27 (2002) $526-528$.

[13] A. Gurr, M. Schwaab, S. Hansen, V. Noack, S. Dazert, Use of the Internet for health information by ENT patients, HNO 57 (2009) 473-479.

[14] M.M. Boston, E. Ruwe, A. Duggins, J.P. Willging, Internet use by parents of children undergoing outpatient otolaryngology procedures, Arch. Otolaryngol. Head Neck Surg. 131 (2005) 719-722.

[15] M.N.K. Boulos, S. Wheeler, C. Tavares, R. Jones, How smartphones are changing the face of mobile and participatory healthcare: an overview, with example from eCAALYX, Biomed. Eng. Online 10 (2011).

[16] N. Lawrentschuk, D. Sasges, R. Tasevski, R. Abouassaly, A.M. Scott, I.D. Davis, Oncology health information quality on the Internet: a multilingual evaluation, Ann. Surg. Oncol. 19 (2012) 706-713.

[17] M. Langille, A. Bernard, C. Rodgers, S. Hughes, D. Leddin, S.V. van Zanten,Systematic review of the quality of patient information on the Internet regardinginflammatory

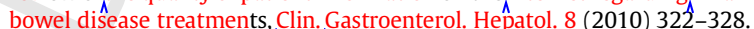

[18] I.G. Chestnutt, Internet-derived patient information on common oral pathologies: is it readable? Prim. Dent. Care 11 (2004) 51-54.

[19] D.D. Pothier, Pâtients and the Internet: are websites on glue ear readable? Clin. Otolaryngol. 30 (2005) 566.

[20] P.G. Volsky, C.M. Baldassari, S. Mushti, C.S. Derkay, Quality of Internet information in pediatric otolaryngology: a comparison of three most referenced websites, Int. J. Pediatr. otorhinolaryngol. 76 (2012) 1312-1316.

[21] P. Hartzbând, J. Groopman, Untangling the Web - patients, doctors, and the Internet, N. Engl. J. Med. 362 (2010) 1063-1066.

[22] K. Khoo, P. Bolt, F.E. Babl, S. Jury, R.D. Goldman, Health information seeking by parents in the Internet age, J. Paediatr. Child Health 44 (2008) 419-423.

[23] B.S. Gerber, A.R. Eiser, The patient-physician relationship in the Internet age: future prospects and thîe research agenda, J. Med. Internet Res. 3 (2001).

[24] R.P. Kessels, Patients' ${ }^{\prime}$ memory for medical information, J. R. ${ }^{\wedge}$ Soc. Med. 96 (2003) 219-222.

[25] S. Henney, S. Rakhra, Patient information in otorhinolaryngology: a prospective audit, JRSM Short Rep. 2 (2011) 37.

[26] L. Pope, P. Silva, R. Almeyda, i-Phone applications for the modern day otolaryngologist, Clin. Otolaryngol. 35 (2010) 350-354. 